2. Future Papers. The next General Meeting would be held on July 18 , at which the Reverend W. L. S. Fleming would read a paper on the glaciological results of the United States Antarctic Service Expedition of 1939-4I. The Committee had that day decided that there should be one more meeting this year, to take place about the beginning of November. No decision had been reached regarding the paper to be read, but if in the meanwhile there were any suggestions these would be welcomed.

3. The President informed members that the International Commission of Snow and Glaciers would meet in Oslo during 1947. (Further particulars will be found on p. 35 of this issue.)

4. The President then asked Mr. J. M. Wordie to take the Chair. Mr. Wordie called upon Mr. G. Seligman to read his paper. Mr. Seligman then read the paper which, together with the discussion, is reported below.

\title{
EXTRUSION FLOW IN GLACIERS
}

$A$ description of tests to prove the hypothesis and some details regarding its influence on glacial erosion

\section{By G. Seligman}

IN the middle of last century, Agassiz, Tyndall and others showed that a glacier flowed faster at its centre than at its margin. Partly from experiments and partly from the assumption that it behaved like a river, it became generally accepted that it also flowed faster at the surface than lower down. This belief was held until ten or fifteen years ago although search through earlier literature shows that evidence was accumulating which might disprove this.

During the thirties of this century several writers began actively to re-examine the question. ${ }^{1}$ In 1937 the late Dr. M. Demorest, ${ }^{2}$ reporting on a West Greenland glacier, wrote that owing to plastic flow the ice was, as it were, forced out from under an ice cap at places where accumulation of snow lay deepest. He cited well-known laboratory experiments showing that ice tended to flow when under differential pressure.

In the following year, Dr. R. Streiff-Becker published his first paper ${ }^{3}$ asserting that in many parts of a glacier, flow was faster below than above.

Demorest used the evidence of glacial striae in old glacier beds. On the other hand Streiff-Becker developed his hypothesis by certain measurements and this paper has been written from material submitted by him.

He had been measuring snow accumulation on the Claridenfirn (Canton Glarus) yearly since 1916 and it occurred to him that if the accumulated firn was not to raise the level of the glacier, it must be carried away faster than appeared from the rate of flow measured at the surface. His measurements of the glacier level showed that the firn moved in waves but that the mean level of the surface was no higher in 1937 than it had been in 1916. Fig. I, p.r3, shows the position of a post, Point 2900 , through which is drawn a line EDC recorded in the

1 See for instance Hollingworth, S. E. Q.F. Geol. Soc. Vol. 87, 1931, p. 345 .

${ }^{2}$ Demorest, M. Zt. Gletscherk. Vol. 24, 1937, p. 45.

${ }^{3}$ Streiff-Becker. R. Zt. Gletscherk. Vol. 25, 1938, p. I. 
field between rock benchmarks on both sides of the glacier. Each year in September ochre was strewn on the snow surface to mark a zero point and in the following September StreiffBecker dug down to the zero point of the previous year and so measured the net surplus of annual accumulation over ablation. The mean annual surplus for the years 1916-37 was $3 \cdot 167$ metres.

The rectangle $\mathrm{ABCD}$ had an area of $\mathrm{r}, 089,200$ square metres. This area multiplied by the mean annual surplus of $3 \cdot 167$ metres gives a total surplus of $3,449,500$ cubic metres. This surplus must find its way through the line $\mathrm{CD}$ in the course of a year if the glacier level is not to be increased.

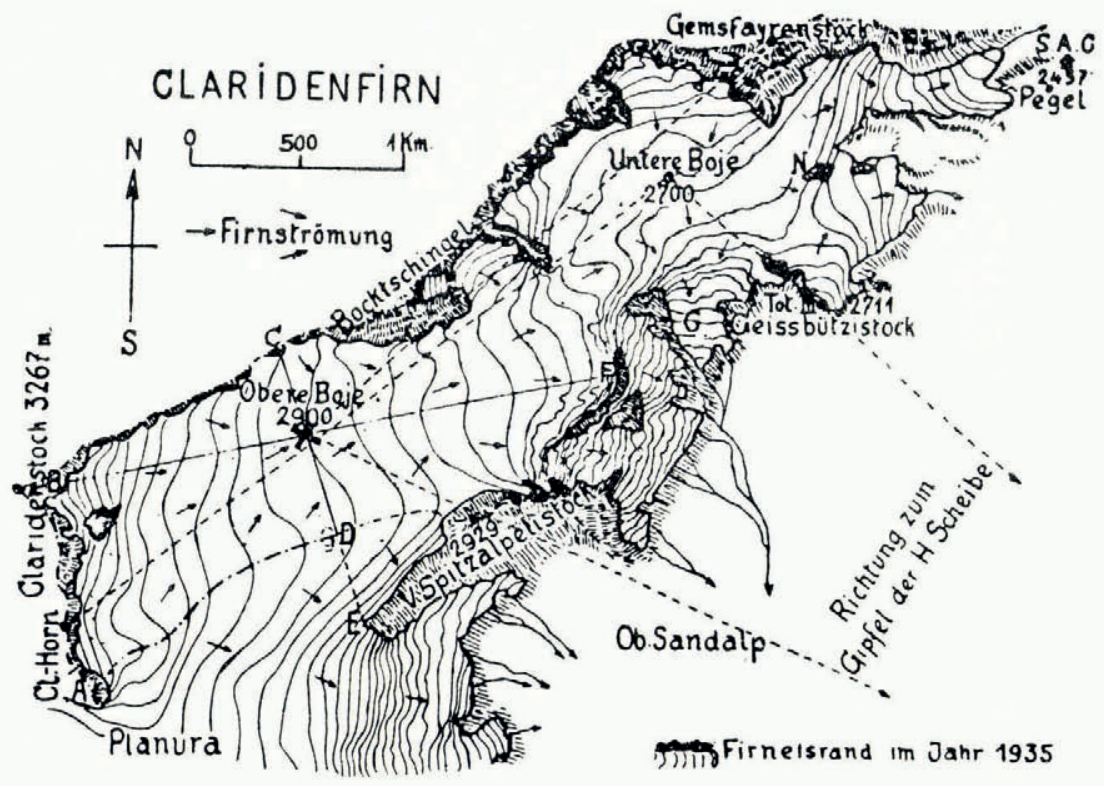

Fig. I. The Claridenfirn showing the area $A B C D$ and the line $E D C$

Now the surface speed of the glacier at Point 2900 was found to average 14 metres per annum. The vertical section through $\mathrm{CD}$ was estimated to be 68,000 square metres (the method by which this estimate was made will be discussed presently). From this it follows that the yearly through-flow beneath the line $C D$ was $68,000 \times r_{4}=952,000$ cubic metres, so that in round figures only I million cubic metres flowed beneath $C D$ instead of the $3 \frac{1}{2}$ million required. Streiff-Becker's argument therefore is that the speed of 14 metres at the surface was not sufficient to remove the year's accumulation and there must be faster flow at lower depths.

The only doubt in the above figures is the area of the glacier section beneath $\mathrm{CD}$. The length $C D$ is 835 metres and Streiff-Becker estimated the depth in the following manner.

"We know," he writes, "the height of Point 2900. We also know the height of the rocks F where the firn breaks off towards the Geissbuetzistock, i.e. 2710 metres (see Fig. 1). By projecting a horizontal line backwards into the hillside, this would give 190 metres of firn thickness, but by taking 
into consideration the inclination of the rocks at the glacier edge, I arrived at the assumption of I 10 metres firn depth at its deepest point and so to a vertical section with an area of 68,000 square metres" (see Fig. 2).

This is equivalent to a mean depth of 63 metres throughout the basin. From my own experience of firn depths supported by research into estimates by many authorities and by the seismic soundings of Washburn, ${ }^{1}$ I believe Streiff-Becker's estimate to be accurate. Let us assume that it is not accurate, that the speed is not greater below the surface than $\mathbf{I} 4$ metres a year and that the glacier at this point flows uniformly at 14 metres throughout its depth. In that case some greater depth is necessary to carry away the surplus. This will be $3,449,500 \div(835 \times 14)=295$ metres which I believe to be an impossible depth at this point in the glacier unless, most improbably, there were a deep hole here and a much faster rate of flow at the margin of the hole. This could be proved by measuring the flow in the centre

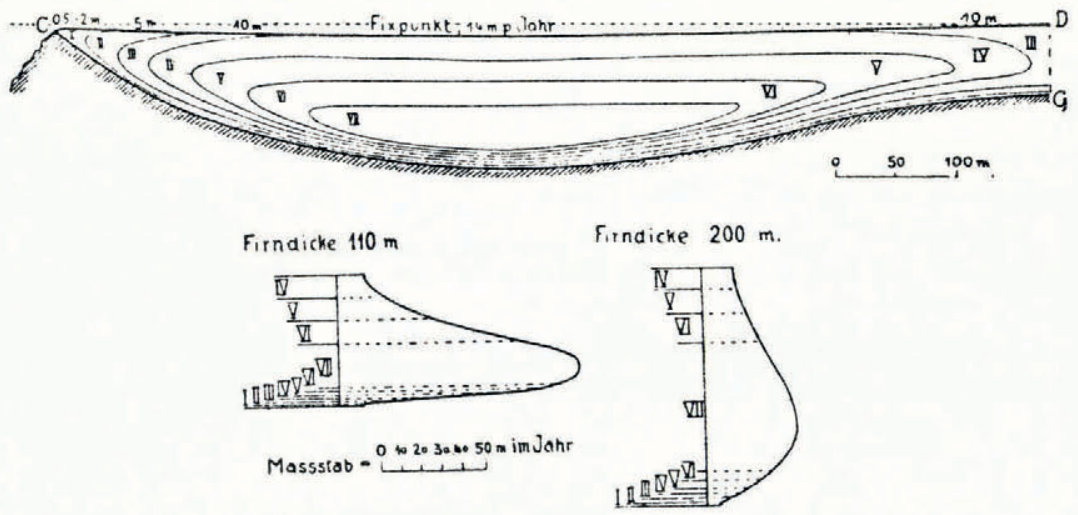

Fig. 2. The upper drawing shows the cross-section of the Claridenfirn from $C$ to $D$ assuming a depth of IIo metres. The line of maximum flow for this depth is shown in the left bottom diagram and on the right for a depth of 200 metres

and at the probable banks of this assumed hole, or better, by taking seismic soundings. Such soundings ought indeed to be made over the whole area and might be of the greatest value in proof or disproof of the thesis.

The only explanation to account for the rate of flow of a glacier being fastest at a point below the surface is that the flow of the ice mass (I use the word loosely to cover snow and ice) is increased by the pressure of the overlying strata. This is in accord with the known properties of ice. ${ }^{2}$ Recently Hoeppler ${ }^{3}$ has shown that at a temperature of $-\mathrm{r} \cdot 0^{\circ} \mathrm{C}$. a single crystal will flow rapidly under a pressure of 7.0 kilogrammes per square centimetre. Somewhat higher pressures would be needed for the ice of a glacier, with its many crystal boundaries ininibiting the flow tendency, but on the other hand the tendency to flow would increase since the temperature would be at or near $0^{\circ} \mathrm{C}$.

1 Washburn, H. B. and Goldthwaite, R. Bul. Geol. Soc. Am. Vol. 48, 1937, pp. 1653-64.

2 See for instance Hawkes, L. Geol. Mag. Vol, 47, 1930, p. i 11.

3 Hceppler, K. Kol. Zeit. Vol. 97 (2), 1941, p. 158. 
Haefeli, one of our greatest authorities on snow and ice, and his colleagues ${ }^{1}$ have shown similar results. Demorest approached the problem from a different angle. By observing the direction of glacial striae ${ }^{2}$ he enunciated, "Ice under sufficient pressure flows in response to the laws of fluid mechanics." He noticed for instance that when ice flow reached an obstruction the striae streamlined round it just as in a fluid.

He recognized two forms of flow (i) gravity flow in cases where the inclination is sufficient to overcome the frictional resistance of the bed but not so great as to cause the ice to break up into an ice fall, and (ii) extrusion flow where the gradient is too low to overcome the frictional resistance, the flow being induced by pressure within the ice mass. ${ }^{3}$ In an ice cap he said that this flow would be "multi-directional beneath the point of greatest accumulation." He subdivided extrusion flow further but I reserve comment on this to-day.

From his observations of glacial striae Demorest calculated that in a glacier stream of true ice of 0.91 specific gravity extrusion flow would become the determining factor when the pressure of the overlying ice reached 4 kilogrammes per square centimetre. This would occur at depths of about 45 metres. A depth of say 60-70 metres would be necessary for extrusion flow to take place in firn with a specific gravity of say 0.7 .

At Point 2900, assuming 100 metres depth of firn with a specific gravity of 0.7 , the pressure of the overlying strata would be about $6 \cdot 3$ kilogrammes per square centimetre, so that extrusion flow could be expected. It should be noted that these figures only take into account the static pressure. There must also be the additional factor of head or dynamic pressure for which no reliable figures are available. It must be said here that Demorest in his calculations made some daring assumptions; but it is nevertheless significant that his figures come so close to Hoeppler's.

Our Jungfraujoch "pin" experiments on firn flow indicate a means of testing the extrusion flow theory. These experiments were made near the surface. If they were repeated at greater depths and carried out quantitively they might tell us much; for instance, whether the actual movement of grain past grain, which we distinctly saw and actually measured, is greater below than at the surface.

Streiff-Becker produces additional arguments in support of his views, namely:

I. It is well known that crevasses never penetrate very deeply into glaciers. I have never seen one deeper than 30 metres. This corresponds exactly with Goldthwait's ${ }^{4}$ observations in North America. Streiff-Becker holds that the upper layers, being rigid or brittle, are easily crevassed, whereas the lower layers flow and do not crack.

2. There is also the partial or complete disappearance of stratification lines in the basal layers of a glacier when seen in section. This, in my opinion, could also be attributed to other causes.

3. Streiff-Becker also attaches considerable importance to the following point. He found that flow in winter was considerably faster than in summer, roughly in the relationship of II : 3 (Haefeli found the same rather surprising fact on the Great Aletsch Glacier ${ }^{5}$ ).

${ }^{1}$ de Quervain, M. "Experientia," Vol. r, Basel, 1945.

2 Demorest, M. Four. Geol. Vol. 46, 1938, pp. 700-25.

${ }^{3}$ Demorest, M. Geol. Soc. Am. Vol. 52, 1941, p. 2025.

4 Goldthwait, R. Fourn. Geol. Vol. 87, 1936, p. 496.

'Haefeli, R. Verh. Schw. Naturf. Ges. 1944, pp. 99-101. 
Streiff-Becker's argument is that somewhere below the surface at a depth where the pressure in summer is not sufficient to cause extrusion flow, the winter's accumulation is just sufficient to turn the balance and bring the critical point of extrusion flow nearer the surface.

4. Then there is the question of "Ogives" or pressure arches about which so much has been written. Streiff-Becker believes that they are formed by the damming up of the rigid upper layers of a tributary against the main stream and, urged on by the swifter undercurrent, form undulations. This, it must be said at once, is quite contrary to the formerly accepted view, but seems to me a more reasonable explanation. ${ }^{1}$

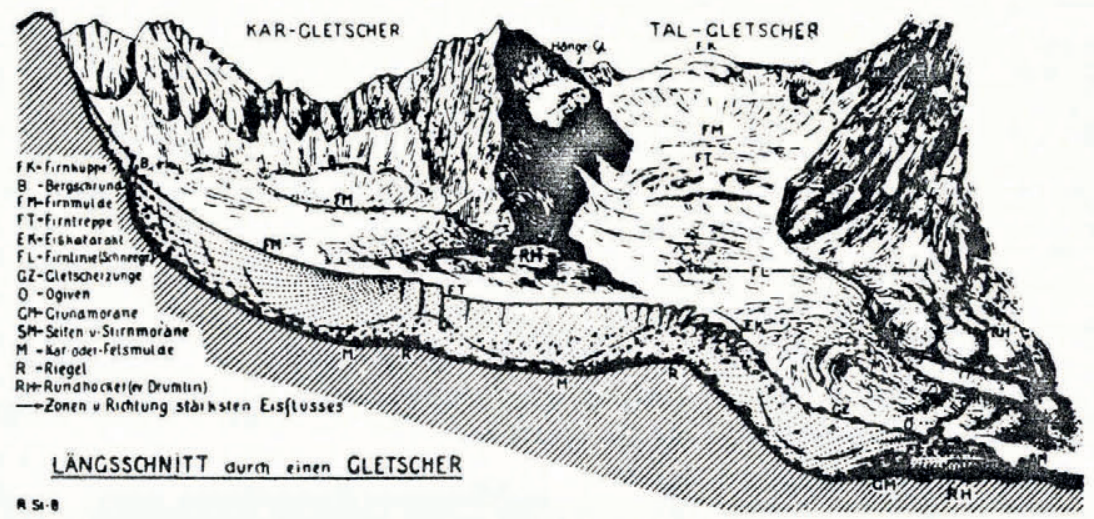

Abb. 13

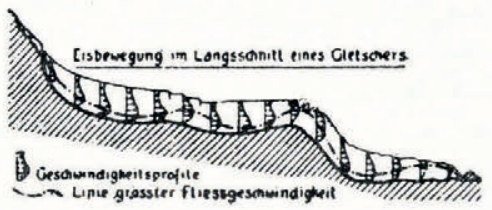

Abb. 14

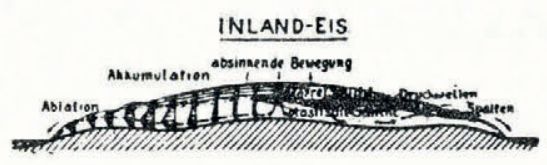

Abb. 15

Fig. 3. Section through an Alpine glacier showing lines of maximum flow according to Streiff-Becker. Bottom right: lines of maximum flow in an ice cap

Let us follow the effects of Streiff-Becker's hypothesis on the glacier. At the top of the system (see Fig. 3, above) we have the ice apron frozen hard to the rock. From the bergschrund to the firn line there is a yearly, wedge-shaped accumulation of snow with its greatest thickness at the upper end and decreasing to nothing at the firn line. Below the firn line there is of course no annual accumulation and all the winter's snow is melted away in summer. The ice of the ice apron may for our present purposes be considered stationary and is too steep to harbour much snow. At the bergschrund the slope flattens out and it is here that snow collects in sufficient quantity for gravitational flow to commence. Attention is drawn to the large quantities of rock and detritus which fall on the glacier near the bergschrund where they disappear from sight to reappear at the surface far down the glacier.

${ }^{1}$ Hess, H. Die Gletscher. Brunswick. 1904, p. 169. 
This morainic material is never found in the crevasse walls of the firn area. In none of our borings in the Mönchfirn, one of which went down roo feet and was only 75 yards from the bergschrund, did we find a single piece of detritus. This I think ought to lead us to agree with the direction of Streiff-Becker's arrows in Fig. 3 and to believe that the detritus is, as it were, sucked down into the glacier in the direction shown. In this diagram the arrows indicate, in Streiff-Becker's views, the line of maximum flow. The downward component in the firn basin has many times been observed, notably by H. F. Reid in $1896.1^{1}$ Reid here quoted Pfaff ${ }^{2}$ who believed he observed a downward flow of as much as $40^{\circ}$ in the névé area of the Great Aletsch Glacier in 1875 .

The detritus at this point would be angular and therefore with great erosional power, so that it would tend to wear away the glacier bed sharply hereabouts. (If this should prove to be in fact the case, it would be an interesting commentary on W. V. Lewis' hypothesis of Cirque Formation. ${ }^{3}$ ) Farther down the detritus becomes blunter and erosion is reduced, so that the glacier bed flattens out. The effect of this step combined with a faster flow of the ice beneath the surface, tends to make the glacier strata, originally level or dipping downstream, rise towards the glacier surface. This phenomenon is always noticeable in glaciers but has never been satisfactorily explained, not even, in my view, by the careful arguments based on Finsterwalder's concept, which however has the support of F. Loewe.

The ice flowing over this step will tend to thin out. As a result the pressure is decreased and the line of maximum flow rises to the surface. As time goes on the hollow becomes deeper and the step higher and as the ice presses over it the upper, more rigid layers, slide over as an ice fall. At the foot of the fall the static pressure, and consequently the fluidity of the lower layers, are increased. The resulting gain in speed enhances the erosive powers of the morainic material so that we get another hollow in the glacier bed.

Above the firn line and almost up to the bergschrund the chief agent of erosion is glacial detritus, but as we near the tongue, water plays a more and more important part. At the same time the detritus, being more rounded, is a less effective agent of erosion. When this blunted material begins to collect in large quantities on the glacier bed the plastic-flowing underlayer is slowed up by friction; also ablation causes a reduction in ice depth. As a result of these two factors the line of maximum flow rises to the surface and the upper ice moves on, largely by shearing action rather than plastic flow.

It will be seen from the foregoing that wherever the pressure of the ice is increased, the line of maximum flow tends to become lower in the glacier and the glacier bed is deepened. This would occur where, for instance, a tributary glacier joins the main stream or where the valley narrows or turns sharply.

The foregoing processes seem to explain the many steps found in glaciated valleys more satisfactorily than previous theories. C. D. Holmes ${ }^{4}$ is certainly of this view and ascribes the deepening of valleys in New York State to "abundant snowfall within the marginal areas of the glacier which causes increased flow in its lower layers."

It has been suggested that these steps may be due to periodic fluctuation in glacier volume. I think however that steps, valley lakes and corrie tarns and perhaps even fjords

${ }^{1}$ Reid, H. F. Journ. Geol. Vol. 4, 1896, p. 921.

2 Heim, A. Handbuch der Gletscherkunde. Stuttgart. 1885, p. 184.

${ }^{3}$ Lewis, W. V. Geog. Review, Vol. 30, 1940, p. 8 I.

'Holmes, C. D. Am. Fourn. Science, Vol. 5, No. 33, 1937, p. 217. 
can be more adequately accounted for by the extrusion flow hypothesis. Such steps are of general occurrence in glaciated valleys and extrusion flow, if it exists at all, must also invariably be present in any sizeable glacier. On the other hand, the conditions postulated by other theories for the formation of tarns and steps are not invariably present and in some cases are often conjectural. I am of course aware that we must not overlook the differential erosion of strata more resistant than their neighbours.

In conclusion, I will briefly refer to Streiff-Becker's line of maximum flow in an ice cap. Theoretically at the centre of an ice cap there can be no flow. It will gradually commence as shown in Fig. 3 and become reduced again as the ice thins. In consequence it is suggested that the site of a former ice cap will have a hump for its centre surrounded by an annular depression. Streiff-Becker cites the sea bed of Hudson Bay as conforming generally with this-a fact which supports the view that a large ice cap was centred upon that region. This line of reasoning must still remain somewhat speculative until we know more about the erosive power of ice caps, for it seems clear that they must carry less subglacial detritus than valley glaciers.

I have put forward the extrusion flow hypothesis. While there is much to be said in its favour and while it is supported by many eminent glaciologists, my personal opinion is that it cannot be finally accepted without further observational research. Nevertheless, the observations and the arguments are sufficiently compelling to justify serious consideration.

\section{DISCUSSION}

Mr. W. V. Lewis expressed strong doubt as to whether all the ice passed through the line CD (see Fig. I, p. 13). The photograph suggested that the glacier flowed along a ledge and that some of the ice fell away transversely instead of crossing the line. A glacier enclosed on both sides would have been a happier choice for such important observations.

Mr. G. Seligman said that this had occurred to him too and that he had had a long correspondence with Dr. Streiff-Becker on the subject. The latter had said that there was a pronounced longitudinal ridge and that no ice in the rectangle $A B C D$ could cross this ridge and by-pass the line CD. Mr. Seligman agreed that the matter presented a difficulty but that Streiff-Becker had held to his point.

Dr. N. E. OdelL asked if this was the only glacier Streiff-Becker had investigated.

Mr. SELIGMAN thought it was, but said Demorest had drawn his conclusions from many glaciers.

Mr. LEwIS asked how much of the sinking in the firn area was due to settling of the firn and what was the density of the surface layers.

Mr. Seligman thought that a little below the surface the density would be 0.5 or 0.6 . At this point compacting would probably not produce any higher gravity than about 0.75 . He pointed out however that the firn surplus was measured by the ochre bands in the pits at the end of each summer after the firn had done most of its settling.

Dr. Perutz said that Streiff-Becker balanced the combined effects of ablation, settling and flow on the one hand and the annual accumulation on the other; he thus found a very large excess of snow. Even if the specific gravity were raised from 0.6 to 0.8 , this would only reduce the surplus by about six-eighths and would not get rid of the whole surplus accumulation.

Dr. K. Sandford, Professor Rudmose Brown, and others were not satisfied that in the photograph of the ochre sections any depths approaching the mean of $3 \cdot 167$ metres was apparent. It looked less than I metre. 
Dr. Perutz also thought that the photograph was misleading and suggested that some of the bands might be ice and not ochre bands.

Mr. LEwIS asked whether under conditions of extrusion flow ice could move uphill for any considerable distance. Penck had said that for a glacier to move the centre of gravity of the ice must everywhere move downhill, i.e. the surface of a glacier must slope seawards more steeply than the reversed slope of the valley floor tilted landwards. These conditions did not seem to apply in some of the diagrams shown.

Mr. Seligman said that some of the drawings were probably exaggerated.

Mr. W. H. WARD said that he thought he might be able to clear up some of these questions by showing some slides which demonstrated the analogies between the motion of unstable clay slopes and that of glaciers. He had recently been reading about some of the work that Dr. Haefeli had been doing and Mr. Seligman's talk that night had helped him a great deal in understanding the work. The metamorphosis of clay sediments was analogous to that of snow. The clay particles settled down in still water in the form of a mud and as more mud was added the load increased. This squeezed the particles closer together and the water was expressed, so that the material became

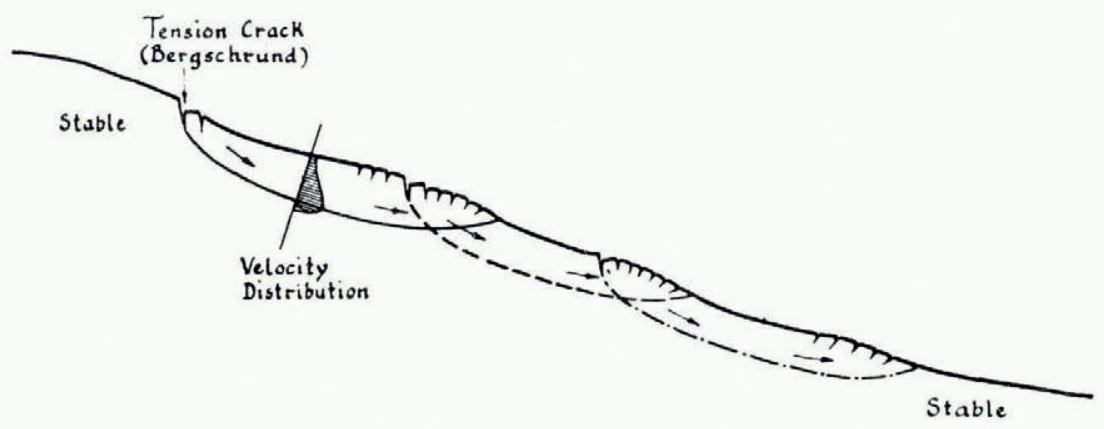

Fig. 4. Movements of a clay slope with a thin softened surface layer

denser and stronger. At great depths the mud became a stiff clay, whilst the soft snow changed to ice. Mr. Ward believed Mr. Seligman had omitted to mention the work of Professor J. Forbes who had written some interesting letters on glaciers. One of the points he raised was that in 1848 he had been reading the work of a French Engineer, Alexandre Collin, who had had some landslips in his reservoir banks. As Forbes pointed out, the similarity between this slip and some of the glacier sections, such as they had seen that night, was striking.

At the top of the slope was a tension zone causing a vertical tension crack, as at the bergschrund (see Fig. 4, above). Below this crack or cracks, the clay moved more or less vertically downwards, whilst towards the toe the clay was thrust upwards and the movement continued until a state of rotational equilibrium was established. The surface slope just above the toe would be reversed on occasions, but the centre of gravity of the whole moving mass, of course, moved downhill. If more clay were added at the top, which was analogous to the accumulation of snow, the equilibrium was again upset and corresponding upheaval occurred at the toe. The glacier toe, in addition, melted away and disturbed equilibrium from below. The velocity or movement distribution with depth in a rotational slip was broadly similar to that mentioned by the lecturer, namely the translation parallel to the general surface slope increased downwards and stopped abruptly at the slip plane. However, even closer analogies with the extrusion flow of glaciers were obtained when there was a shallow depth of soft weathered clay on a long slope. The strength of the material increased 
abruptly with depth and then a succession of shallow rotational movements merging one into the other became evident.

Mr. Seligman asked what was meant by the strength of material.

Mr. WARD said he meant the existing ultimate shear strength. He had not been able to find out exactly the mechanical properties of snow and ice but believed that dry snow was frictional, that is to say its shear strength was entirely pressure-conditioned, whereas ice seemed to be a material of constant shear strength and behaved rather like a plastic clay.

Mr. Seligman said that when Mr. Ward stated that it developed strength by shear he was not clear what analogy the latter drew between clay and ice which was now thought to have greater flow at depth.

Mr. WARD replied that the drawing he had made (Fig. 4) illustrated the analogy and could be compared with Streiff-Becker's diagram. The reason that at any one section the motion was greater at depth was that the shear strength was not pressure-conditioned. Therefore it was only at depth that the body forces produced shear stresses greater than the shear strength.

Professor W. B. R. KING referred to the steps in the glacier and the topography of glaciated uplands. He inquired whether it was not more probable that the effect of extrusion flow had been rather to accentuate the changes of slope than to initiate them. Their origin might be due to differential weathering of contiguous strata or, more likely, to periodic up-moves of mountain masses. He thought however that a great deal of help would be gained by geomorphologists from the extrusion flow hypothesis.

Dr. S. E. Hollingworth said that as reference had been made to the uphill movement of glacier ice he would make a special plea for taking into consideration the evidence from the study of the areas occupied by the last ice sheet of the Pleistocene glaciation. Here were preserved in great detail and precision the movements of the basal layers in ice-moulded drumlins, striations, etc. In north-west England the Vale of Eden provided a good example of the uphill movement of ice from a basal ice parting at 500 feet O.D. to over 1400 feet O.D. across the Stainmore Col. All the evidence from such an area had been held to imply a deep zone of relatively fluid ice flowing under conditions that appeared to approach those in which the laws of hydrostatics would be applicable. At the same time the upper layers moved-often in widely different direction from those below-under conditions familiar in the near surface layers of modern glaciers and ice sheets. The topographic relief was that of a basin-like lowland with a mountainous rim, the whole being buried in ice at the last maximum to a height of 2000-2500 feet O.D. Through cols or gaps in the rim of the basin the lower plastic layers flowed freely under the pressure due to the weight of the thick ice above, while the upper layers moved outwards in the direction of surface slope. These movements appeared to fit closely with those which might be expected from Streiff-Becker's work and were consistent with Demorest's extrusion flow and gravity flow hypothesis. In terms of the work of those authors and their knowledge of the physics of ice movement from the Jungfraujoch and other studies, the whole conception of differential movement in such an ice sheet was capable of much clearer and more precise interpretation than hitherto.

Mr. Lewis asked Dr. Hollingworth whether the drumlins were not due to the last phases of glaciation and how it could be ascertained that the erratics moved at the same time.

Dr. HollingwORTH replied that all the drumlins must have been formed primarily at maximum glaciation. There was no evidence of their modification. It was believed that the last glacier died away through loss of replenishment at the source and not primarily from the effect of melting action.

Dr. Perutz said that he wished to stress that Streiff-Becker's views on glacier flow were fully consistent with the results of certain war researches on the mechanical properties of ice. The allies 
had planned at one time to build large aircraft-carriers of ice, and for this purpose extensive investigations into the properties of ice were carried out. This brought to light a phenomenon technically known as "creep," that is to say the ice was permanently deformed under the influence of comparatively small stresses. This had been known for a long time and used to be attributed to regelation. Dr. Perutz's experiments in connection with the Bergship project showed that creep occurred at all temperatures down to $-20^{\circ} \mathrm{C}$., and moreover, that the loads required for producing measurable creep rates were extremely low. For instance, at a pressure of 2.7 kilogrammes per square centimetre corresponding to a hydrostatic pressure at a depth under the glacier surface of only a hundred feet, creep would be measurable at $-10^{\circ} \mathrm{C}$. and would become fairly rapid at the melting point. It must be expected that large masses of ice would sag under their own weight. In other words, if the morphology of a glacier bed was such that energy could be gained by extrusion flow, it must be expected to occur, even in a relatively shallow glacier like the Claridenfirn, and much more so, of course, in large ice caps. At present their knowledge of the creep properties of ice was still insufficient to calculate the rate of extrusion flow under given conditions of depth, density and temperature distribution. More experiments in the laboratory would be needed before quantitative predictions of this type could be made. Dr. Perutz wished to suggest that both plastic flow and slip over thrust planes, such as had been observed in clay, might occur in glaciers. At great depths the ice, being under a high load, would yield plastically, while the comparatively brittle character of the ice near the glacier surface might favour the formation of thrust planes.

Dr. Odell said that Dr. Perutz had put his finger on several important aspects of the question, particularly in regard to thrust planes where obstruction to glacial flow might exist. He asked Mr. Seligman whether Streiff-Becker had formulated the same hypothesis of extrusion flow as Demorest including the idea of "obstructed" extrusion flow.

Mr. Seligman thought it likely that Streiff-Becker had not had the opportunity to study Demorest's work. As to "obstructed extrusion flow" he felt that this raised so many points of difficulty and controversy that with Dr. Odell's permission he would prefer not to go into it at the end of this very long discussion.

Dr. Perutz said it would be possibie to study glacier flow by making small ice models and spinning them in a centrifuge; since it was not possible to measure flow at great depth in a glacier an attempt should be made to imitate conditions that would prevail there with model experiments.

Mr. WarD observed that when he had carried out his experiments with soil he had in fact swung the material round in a bucket.

To sum up the discussion, the meeting paid tribute to the valuable observations carried out over so many years by Dr. R. Streiff-Becker. At the same time the feeling appeared to be that the value of the figures adduced by him would have been strengthened had his measurements of firn flow and calculations been carried out over the whole breadth of the glacier, and if the contraction of the snow mass by settling had been taken into account. Nevertheless his views carried great weight and were well backed up by the physical facts which fully supported his hypothesis, even though more work seemed necessary before it could be finally accepted.

At the conclusion of the discussion Mr. Wordie thanked the lecturer and those who had taken part in the discussion, especially Mr. Ward, Dr. Perutz and Dr. Hollingworth. He commented on the value of these exchanges of ideas in clarifying the position. 